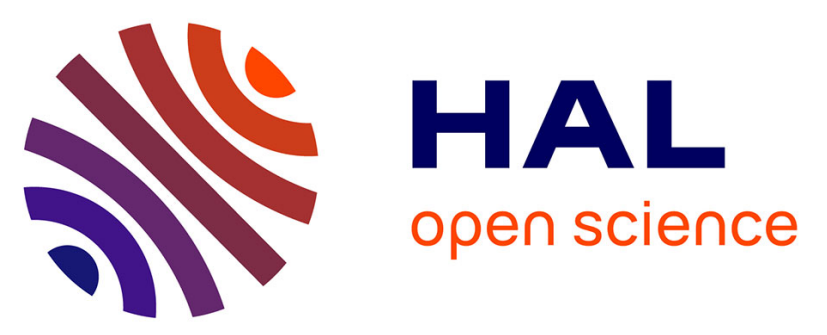

\title{
A first-generation microsatellite-based integrated genetic and cytogenetic map for the European rabbit ( Oryctolagus cuniculus) and localization of angora and albino
}

Céline Chantry-Darmon, Celine C. Urien, Hubert de Rochambeau, Daniel D. Allain, Bérengère Pena-Arnaud, Hélène Hayes, Cécile Grohs, Edmond E. Cribiu, Severine Deretz, Catherine Larzul, et al.

\section{- To cite this version:}

Céline Chantry-Darmon, Celine C. Urien, Hubert de Rochambeau, Daniel D. Allain, Bérengère PenaArnaud, et al.. A first-generation microsatellite-based integrated genetic and cytogenetic map for the European rabbit ( Oryctolagus cuniculus) and localization of angora and albino. Animal Genetics, 2006, 37, pp.335-341. hal-02659000

\section{HAL Id: hal-02659000 \\ https://hal.inrae.fr/hal-02659000}

Submitted on 30 May 2020

HAL is a multi-disciplinary open access archive for the deposit and dissemination of scientific research documents, whether they are published or not. The documents may come from teaching and research institutions in France or abroad, or from public or private research centers.
L'archive ouverte pluridisciplinaire HAL, est destinée au dépôt et à la diffusion de documents scientifiques de niveau recherche, publiés ou non, émanant des établissements d'enseignement et de recherche français ou étrangers, des laboratoires publics ou privés. 


\title{
A first-generation microsatellite-based integrated genetic and cytogenetic map for the European rabbit (Oryctolagus cuniculus) and localization of angora and albino
}

\author{
C. Chantry-Darmon*, ${ }^{\dagger}$, C. Urien* ${ }^{*}$, H. de Rochambeau ${ }^{\ddagger}$, D. Allain ${ }^{\ddagger}$, B. Pena ${ }^{\ddagger}$, H. Hayes ${ }^{\dagger}$, C. Grohs ${ }^{\dagger}$, E. \\ P. Cribiu ${ }^{\dagger}$, S. Deretz-Picoulet ${ }^{\S}$, C. Larzul" , J. C. Save* , A. Neau ${ }^{\uparrow}$, P. Chardon* and C. Rogel-Gaillard* \\ *Laboratoire de Radiobiologie et Etude du Génome, UMR INRA CEA 314, Domaine de Vilvert, 78350 Jouy-en-Josas, France. 'Laboratoire \\ de Génétique Biochimique et Cytogénétique, Domaine de Vilvert, 78350 Jouy-en-Josas, France. ${ }^{\ddagger}$ Station d'Amélioration Génétique des \\ Animaux, INRA, BP27, 31326 Castanet-Tolosan Cedex, France. ${ }^{\S}$ GEPA INRA Le Magneraud, 17700 Surgères, France. "Station de Génétique \\ Quantitative et Appliquée, INRA, Domaine de Vilvert, 78350 Jouy-en-Josas, France
}

\section{Summary}

\begin{abstract}
Although the European rabbit (Oryctolagus cuniculus) is used both in agronomics and in research, genomic resources for this species are still limited and no microsatellite-based genetic map has been reported. Our aim was to construct a rabbit genetic map with cytogenetically mapped microsatellites so as to build an integrated genetic and cytogenetic map. A reference population of 187 rabbits comprising eight three-generation families with 10-25 offspring per family was produced. One hundred and ninety-four of 305 previously identified microsatellites were included in this study. Of these, 158 were polymorphic with two to seven alleles. The map reported here comprises 111 markers, including 104 INRA microsatellites, five microsatellites from another source and two phenotypic markers (angora and albino). Ninety markers were integrated into 20 linkage groups. The remaining 21 microsatellites mapped to separate linkage groups, 19 with a precise cytogenetic position and two with only a chromosomal assignment. The genetic map spans $2766.6 \mathrm{cM}$ and covers 20 rabbit chromosomes, excluding chromosomes 20,21 and X. The density of this map is limited, but we used it to verify the location of angora and albino on chromosomes $15 \mathrm{q}$ and 1q, respectively, in agreement with previously published data. This first generation genetic/cytogenetic map will help gene identification and quantitative trait loci mapping projects in rabbit.
\end{abstract}

Keywords albino, angora, chromosomes, cytogenetic map, genetic map, linkage, microsatellites, rabbit.

\section{Introduction}

The European rabbit (Oryctolagus cuniculus) is a valuable mammalian species to humans both as a domestic and wild animal (Lebas et al. 1997). Wild O. cuniculus is a popular game animal, especially in Europe, and many domestic $O$. cuniculus breeds and strains are raised commercially for meat, wool and fur and as pets. Rabbit breeding corresponds to a small but active economic sector; i.e. the worldwide

Address for correspondence

C. Rogel-Gaillard, Laboratoire de Radiobiologie et Etude du Génome, UMR INRA CEA 314, Domaine de Vilvert, 78350 Jouy-en-Josas,

France.

E-mail: claire.rogel-gaillard@jouy.inra.fr

Accepted for publication 31 March 2006 production of meat reaches 1 million tons in carcass weight per year, with 50\% produced in Europe and 30\% in China (Magdelaine 2003). Rabbit skins and pelts, by-products of meat, are used as fur and for the manufacture of felt, with global production estimated at one billion per year (Lebas et al. 1997). In addition, the domestic rabbit is used as a laboratory animal and contributes greatly to biological and medical research. Given the importance of rabbits in many domains, it is surprising how slow the development of genomic resources has been for this species. A first step was taken in August 2004 with the announcement by the National Human Genome Research Institute (USA) of a program for the partial sequencing of the rabbit genome, together with that of eight other mammals (http:// www.nih.gov/news/pr/aug2004/nhgri-04.htm). A genome sequence with threefold coverage is now available at 
(http://www.ncbi.nlm.nih.gov/entrez/query.fcgi?db=geno meprj\&cmd $=$ Retrieve\&dopt=Overview\&list_uids $=12818$ ) and will help future mapping projects.

The genetic map is still very limited in this species, with only one partial map (Fox 1994; Korstanje et al. 2001, 2003) comprising 77 morphological, biochemical and molecular makers distributed in 15 linkage groups, among which only seven are anchored onto chromosomes. In addition, amplified fragment length polymorphism (AFLP) markers were used to identify a quantitative trait locus (QTL) for serum high density lipoprotein (HDL) cholesterol in rabbit (Van Haeringen et al. 2001) and subsequently to construct a genetic map based on 103 AFLP markers organized into 12 linkage groups (Van Haeringen et al. 2002).

In 2001, l'Institut National de la Recherche Agronomique (INRA, France) launched a rabbit genome mapping program for the future development of projects aimed at mapping QTL and identifying candidate genes for production traits. Our objective was to build an integrated cytogenetic and genetic map based on microsatellites regularly distributed over the rabbit genome. First, a standardized rabbit R-banded karyotype was established for precise and consensus fluorescence in situ hybridization (FISH) mapping (Hayes et al. 2002), and then 257 genes were FISH mapped (Chantry-Darmon et al. 2003, 2005a) with rabbit bacterial artificial chromosome (BAC) clones from an INRA library (Rogel-Gaillard et al. 2001). These localizations confirmed and/or refined most of the human-rabbit comparative data based on reciprocal chromosome painting (Korstanje et al. 1999). In parallel, 305 microsatellite sequences were produced either from gene-containing BACs with a known cytogenetic location or from a randomly produced genomic plasmid library (Chantry-Darmon et al. 2005b). One hundred and eighty-three of these 305 microsatellites were cytogenetically anchored across all the rabbit chromosomes except chromosome 22. In the present work, we report the genetic characterization of these microsatellites, including their polymorphism level and linkage analysis in rabbit reference families produced especially for this project. Parental strains of rabbits carrying wild and mutant alleles for angora and albino were chosen to construct these families. This allowed us to validate the relevance of the resulting genetic map by mapping the albino and angora characters for which preliminary mapping information was available.

\section{Materials and methods}

\section{Animal resources}

Three rabbit INRA strains were used to build three-generation families (Fig. 1), namely INRA2066 (de Rochambeau 1998), Castor Orylag ${ }^{\circledR}$ (INRA, Paris, France) (Vrillon et al. 1998) and Laghmere ${ }^{\circledR}$ (INRA, Paris, France). Strain INRA2066 carries two copies of the wild-type allele at the angora locus $(L L)$ and two copies of the recessive himalayan allele $\left(c^{h} c^{h}\right)$ at the albino locus. The Orylag ${ }^{\circledR}$ strain is wild type both at the angora locus $(L L)$ and at the agouti colour locus $(C C)$, while the Laghmere ${ }^{\circledR}$ strain carries recessive alleles at these respective loci (II) and ( $c c)$, where $c c$ confers the albino colour (Fig. 1). Two crosses were carried out to produce the F1 generation: (i) eight INRA2066 males with 22 Laghmere $^{\circledR}$ does and (ii) three Laghmere ${ }^{\circledR}$ males with 12 Castor Orylag $^{\circledR}$ does. The 53 F1 does from the (i) cross were then mated with the $29 \mathrm{~F} 1$ males from the (ii) cross, which produced $853 \mathrm{~F} 2$ rabbits. The following parameters were registered for each F2 individual: sex, weight at 63 days, hair length, texture, diameter and colour. Four phenotypic traits segregated in the families: two hair texture

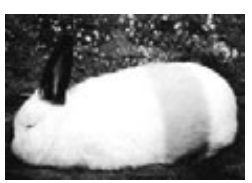

INRA2066

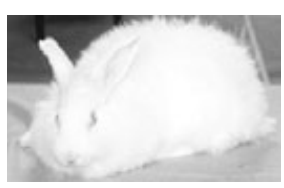

Laghmere $^{\circledR}$

$F_{0}$

8 (5) males $L L c^{h} C^{h}$
22 (8) does

IlcC

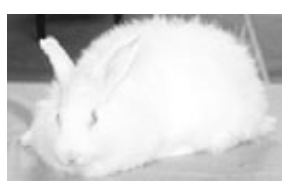

Laghmere $^{\circledR}$

3 (3) males

IlcC

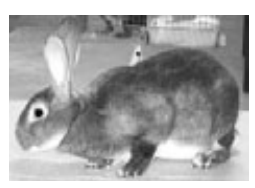

Orylag $^{\circledR}$

12 (4) does

LLCC

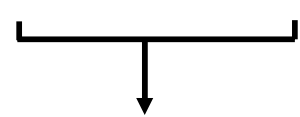

$F_{1}$

53 (8) does

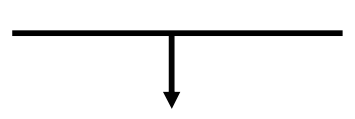

29 (8) males

Figure 1 Structure of the reference rabbit families. Two phenotypic traits segregate in the families: angora, with wild-type $(L)$ and mutated $(I)$ alleles, and albino, with wild-type $(C)$, albino $(c)$ and himalayan $\left(C^{h}\right)$ alleles. The total number of animals is indicated, and the number of animals selected for genotyping and linkage analysis is given in parentheses. 
characters (i.e. angora and normal) and two colour characters (i.e. albino and agouti). The segregation patterns of wild type $(L)$ and recessive (l) alleles at the angora locus and of three alleles (wild type, C; albino, $c$; himalayan, $c^{h}$ ) at the albino locus were observed to determine the genetic positions of these loci.

\section{Microsatellite resources}

From 305 initial sequences (AJ874368-AJ874672), a set of 194 microsatellites, of which 183 were cytogenetically mapped (Chantry-Darmon et al. 2005b), was tested in this study. They are referred to as INRA microsatellites. A second set of seven microsatellite sequences D1Utr4, D3Utr2, D5Utr3, D6Utr4, D7Utr4, D12Utr2 and D19Utr2, assigned to chromosomes 1, 3, 5, 6, 7, 12 and 19 respectively (Korstanje et al. 2001, 2003), were also included and are referred to as Utrecht microsatellites.

\section{Animal genotyping}

DNA was extracted from peripheral blood mononuclear cells recovered from $8 \mathrm{ml}$ of blood sampled on ethylenediaminetetraacetic acid (EDTA) (K3 EDTA, Vacutainer ${ }^{\circledR}$ B-D; Becton Dickinson, Rutherford, NJ, USA) by cardiac puncture, using a protocol described by Jeanpierre (1987). A low-cost technique described by Schuelke (2000) was applied for the genotyping of microsatellites. The polymerase chain reaction (PCR) reaction was carried out with three primers, including a primer specific for the locus to be amplified and extended by a universal sequence of 17 nucleotides (5'GACCGGCAGCAAAATTG-3'), a reverse primer specific for the locus and a universal primer of 17 nucleotides that was 5'-labelled by 6-Fam, Hex or Tet (MWG AG Biotech, Ebersberg, Germany). The PCR protocol has been provided as Appendix S1. The results were analysed with the Genetic Profiler v1.1 software (ABI Prism 377A sequencer; Applied Biosystems, Foster City, CA, USA) or the Genotyper software (MegaBACE 1000 sequencer; Amersham Biosciences, New Haven, CT, USA). Genotyping data were checked using an in-house program (A. Neau, personal communication), which analysed the consistency of the allele distribution of each marker according to pedigrees.

\section{Linkage analyses}

The CRI-MAP 2.4 software (Green et al. 1990) was used to build the genetic map. The first step identified linked markers by a two-point analysis with the two-point option. In the second step, the linkage groups were examined by multipoint analyses using the build and flipsn options. Linkage data were merged with cytogenetic mapping data to confirm the order of markers or to identify linkage of isolated or weakly informative markers. These various analyses were performed with a LOD score of 3 (lowered to
1.8 in a few cases where the cytogenetic position of the markers made it possible to confirm the link). The size of the genetic map was calculated by adding up the genetic distances of all linkage groups plus $15 \mathrm{cM}$ at both ends of each group and including $15 \mathrm{cM}$ on both sides of each unlinked marker. The heterozygosity of each marker was calculated in the $\mathrm{F}_{0}$ population using the formula $1-\Sigma_{i=1}^{n}\left(f_{i}\right)^{2}$, in which $n$ is the allele number and $f_{i}$ equalled the frequency of allele $i$ (ranging from 1 to $n$ ).

\section{Results and discussion}

The objective was to construct a first-generation genetic map of the rabbit using markers at 10- to 20-cM intervals across the genome. Eight families with 10-25 offspring per family were selected among the three-generation rabbit families that were produced for the project (Fig. 1). From a total of 980 rabbits, 187 animals were genotyped, comprising $20 \mathrm{~F}_{0}, 16 \mathrm{~F}_{1}$ and $151 \mathrm{~F}_{2}$ individuals (Fig. 1). Among the 305 INRA microsatellites that were previously isolated in the laboratory, 194 microsatellites were successfully amplified by PCR with the primers already reported (Chantry-Darmon et al. 2005b). From this subset, 158 $(81 \%)$ of the microsatellites were informative in the $F_{1}$ animals from the eight reference families (Table S1) with two to seven alleles $(3.3 \pm 1.0$ on average). Among the seven Utrecht microsatellites reported by Korstanje et al. (2001, 2003), five (D1Utr4, D3Utr2, D5Utr3, D6Utr4 and D12Utr2), mapping to OCU $1,3,5,6$ and 12 respectively were polymorphic with two to five alleles (Table S1). As already reported in rabbit by Queney et al. (2001), a small number of alleles was observed, but this may be due in part to the use of inbred rabbit strains for building the reference families. Heterozygosity was calculated for all the polymorphic markers using $20 \mathrm{~F}_{0}$ animals, except for marker INRACCDDV326, which maps to OCUY (Table S2). This rate ranges from 0.17 (INRACCDDV0101, INRACCDDV0202, INRACCDDV0292) to 0.78 (INRACCDDV0213), with an average value close to 0.50 . This heterozygosity rate agrees with the data reported for other mammals: $50 \%$ in cattle (Bishop et al. 1994), 55-80\% in pig (Rohrer et al. 1994) and 63\% in human (Hudson et al. 1992).

The 163 polymorphic microsatellite markers (158 INRA markers and five Utrecht markers) were genotyped in 187 animals of the reference population. Genotyping data were efficiently analysed for 109 microsatellite makers (Table S2). The genotyping data obtained for the remaining 54 polymorphic markers were difficult to interpret, probably due to the genotyping methodology used and to the standard cycling conditions applied to all the microsatellites. Polymorphic markers excluded from the map are listed in Table S1. These microsatellites might have been rescued either by changing PCR cycling and annealing temperature conditions with the three-primer technique or by using classical PCR conditions with one locus-specific 
fluorescent primer. The resulting genetic map comprised 111 markers, including 109 microsatellites (104 INRA and five Utrecht markers) and the two phenotypic markers angora and albino (Table S2 and Fig. 2). The number of informative meioses varied from 24 to 260 (157 \pm 63 on average) and from 0 to 250 for markers with known phase (94 \pm 63 on average). Eighty-eight microsatellites and the two phenotypic markers were integrated into 20 linkage groups anchored to 17 chromosomes. The linkage groups were referred to as LG followed by the chromosome number and a lower case letter (Fig. 2 and Table S2). The size of the linkage groups ranged from $0 \mathrm{cM}$ (2 markers) to $243.3 \mathrm{cM}$ (11 markers) with an average of $24.9 \mathrm{cM}$. Nineteen polymorphic microsatellites with a cytogenetic localization were not included in any linkage group (Table S2 and Fig. 2). The two microsatellites INRACCDDVO1OO and INRACCDDV0202 were not sufficiently informative to be mapped with certainty. Their most likely position is represented by a line drawn parallel to the linkage groups LG4b and LG13a respectively (Fig. 2). For each of the three chromosomes OCU4, OCU6 and OCU18, two overlapping linkage groups were unlinked (Fig. 2). Genotyping data analysis revealed that this was
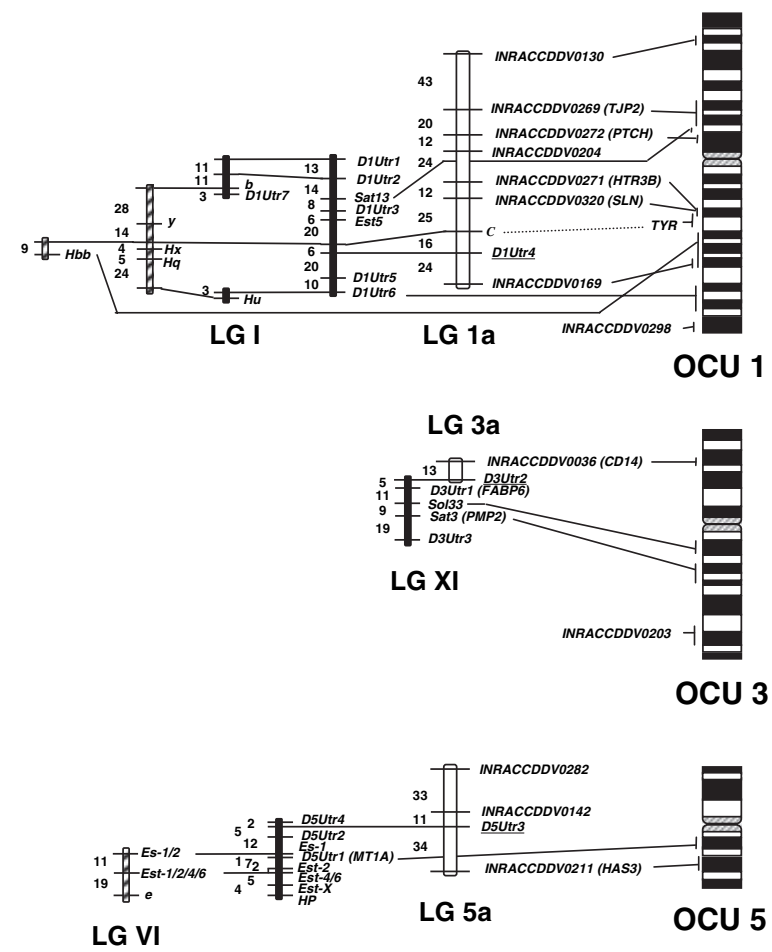

due to microsatellites that were not informative in the same families in each linkage group.

Thirty-six microsatellites, which have been FISH mapped and are associated with an identified gene (Table S2 and Fig. 2; Chantry-Darmon et al. 2005b), provide a direct integration of genetic and cytogenetic data. The size of this genetic map was $2766.6 \mathrm{cM}$ averaged across the male and female maps, which are 2942 and $2930 \mathrm{cM}$ respectively. In order to integrate previously reported linkage groups (Fox 1994; Korstanje et al. 2001, 2003), we included seven Utrecht microsatellites assigned to OCU1 (D1Utr4), OCU3 (D3Utr2 in LG XI), OCU5 (D5Utr3), OCU6 (D6Utr4), OCU7 (D7Utr4), OCU12 (D12Utr2) and OCU19 (D19Utr2) (Table S1 and Fig. 2). Only five were interpretable and polymorphic. The D1Utr4 microsatellite allowed us to link LGI established by Fox (1994) and further mapped by Korstanje et al. (2001) on OCU1 (LG1a; Fig. 2). Similarly, D3Utr2 links LGXI to LG3a on OCU3; D5Utr3 links LGVI to LG5a on OCU5; D6Utr4 links LG6a to a linkage group previously assigned to OCU6 (Korstanje et al. 2003) and D12Utr2 anchors LGVII (Fox 1994) to LG12a on OCU12. D6Utr4 was integrated in the linkage group LG6a, which is anchored at both ends on OCU6p and confirms the orientation
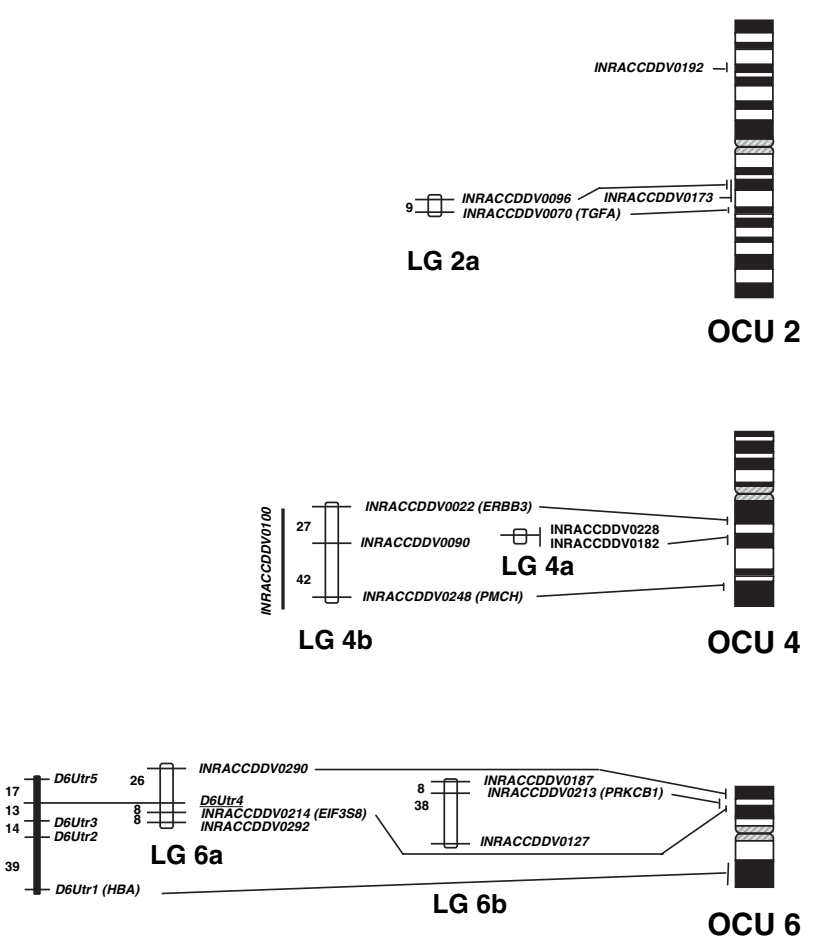

Figure 2 Rabbit integrated genetic and cytogenetic map, including anchorage of previously published linkage groups. The linkage groups are represented on the left side of each R-banded ideogram of rabbit chromosomes. Bars indicate the cytogenetic positions of microsatellites previously mapped by fluorescence in situ hybridization (Chantry-Darmon et al. 2005b). When an associated gene is known, it is given in italicized letters within parentheses. Genetic distances are estimated in Kosambi CM and mentioned on the left of the linkage groups. The new linkage groups have names referred to in Table S2 and are represented by open boxes. The linkage groups reviewed in Fox (1994) are represented as hatched boxes, and the linkage groups reported by Korstanje et al. $(2001,2003)$ are represented as large black bars. The two microsatellites INRACCDDV0100 and INRACCDDV0202, which could not be precisely positioned in linkage groups, are written to the left of a bar representing the most likely position. The morphological characters albino $(C)$ and angora $(L)$ were mapped to linkage groups LG1a and LG15a respectively. 
Figure 2 (continued)
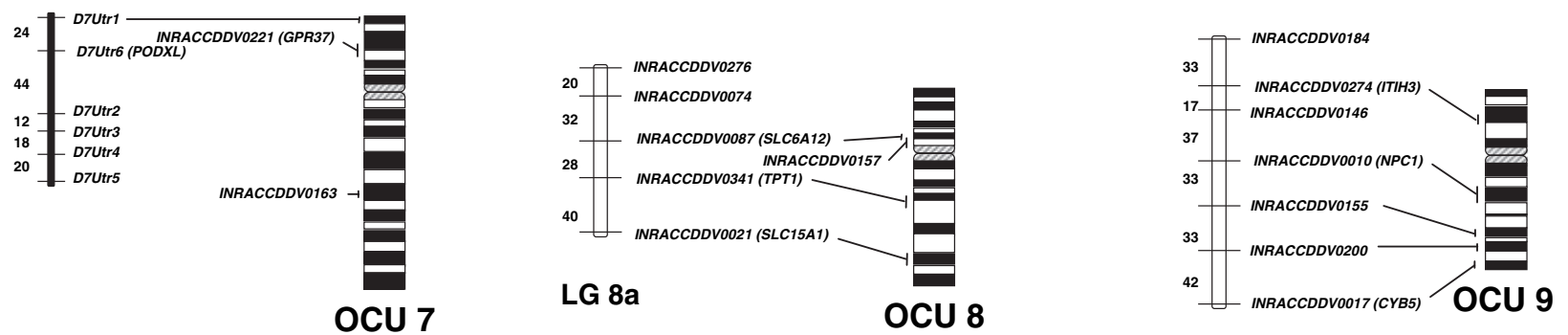

\section{LG 9a}
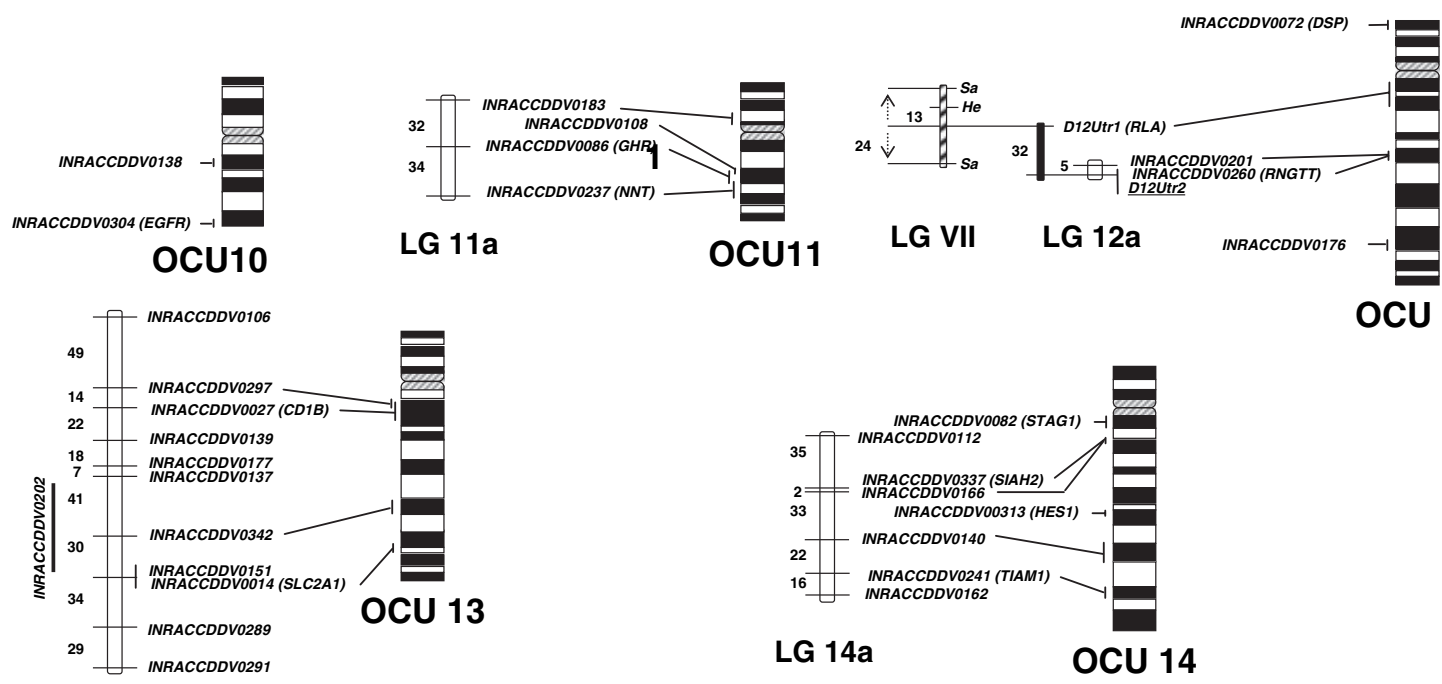

OCU 12

LG 13a

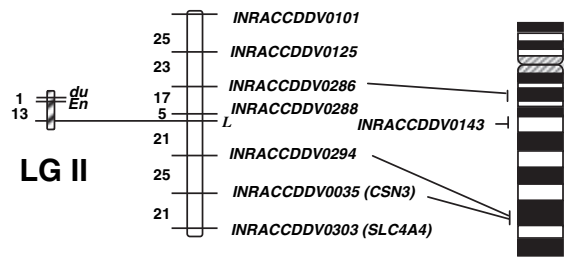

LG 15a OCU 15

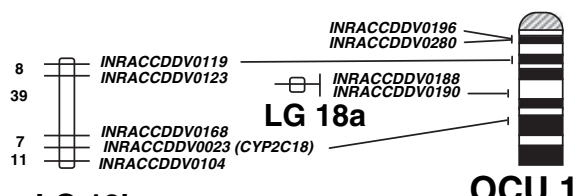

LG 18b
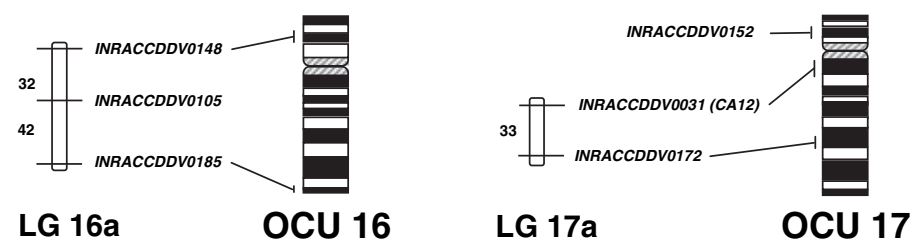

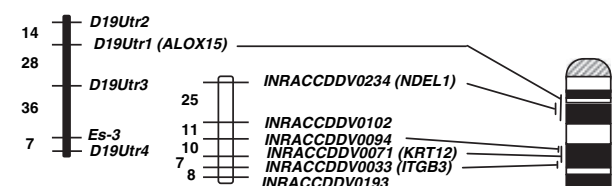

LG 19a
OCU 19
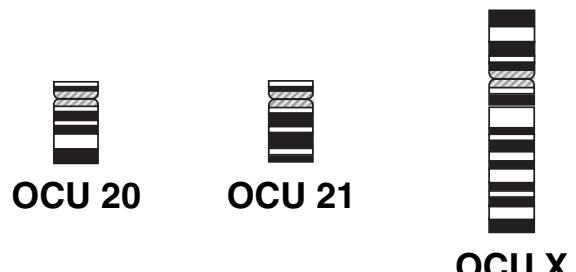

INRACCDDV0326 (SRY)

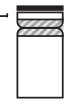

OCU Y 
of the linkage group reported by Korstanje et al. (2003). For chromosomes 7 and 19, the previously identified linkage groups could not be integrated in our genetic map but are represented in Fig. 2. The angora phenotypic marker made it possible to link LG15a to LGII (Fox 1994) on OCU15.

The angora character mapped $3 \mathrm{cM}$ from INRACCDDV0288 by a two-point analysis (LOD $=7.63)$. Multipoint analysis revealed that the angora character belongs to the linkage group LG15a on OCU15 between microsatellites INRACCDDVO288 and INRACCDDVO294 at 4.8 and $20.7 \mathrm{cM}$ respectively (Fig. 2 and Table S2). In mice, the angora phenotype is due to an autosomal recessive mutation in FGF5 (Hebert et al. 1994). The FGF5 gene is localized on human chromosome 4q21.21 (Ensembl Human Genome Browser 27.35a.1), which is conserved with rabbit chromosome $15 \mathrm{q}$, according to the human-rabbit comparative map (Korstanje et al. 1999). Moreover, our results agree with those of Mulsant et al. (2004) revealing a tight genetic linkage between the angora character and the FGF5 gene in rabbit, although no causative mutation has been identified.

The albino character mapped $14 \mathrm{cM}$ from D1Utr4 by twopoint analysis $(\mathrm{LOD}=18.62$ ), and it belongs to the linkage group LG1a on OCU1, between microsatellites INRACCDDV0320 and D1Utr4 at 25.2 and $16 \mathrm{cM}$ respectively. The linkage analyses reported here provide a genetic linkage with LGI, which contains the haemoglobin beta chain $(\mathrm{Hbb})$ locus (Fig. 2). Mutations of the tyrosinase (TYR) gene are responsible for the albino phenotype in mouse (Beermann et al. 1990), human, rat, cow, dog and chicken (OMIM \#203100). In addition, the rabbit TYR gene has been mapped previously by FISH on OCU1q14-q15 (Chantry-Darmon et al. 2005a) and the Hbb locus has been mapped on OCU1q14-q21 (Xu \& Hardison 1989). These cytogenetic data agree with the genetic linkage analyses (Fig. 2), and our results confirm a previous report demonstrating genetic linkage between albino and $H b b$ with an estimated map distance of $9 \pm 6 \mathrm{cM}$ (Sandberg \& Andersson 1987). The TYR gene variants are probably involved in fur pigmentation of rabbit (Aigner et al. 1996, 2000), and indirect experiments strongly suggest that the TYR gene variants are responsible for the albino phenotype because albinism was rescued in transgenic rabbits by introducing a yeast artificial chromosome containing the mouse tyrosinase gene by pronuclear injection (Brem et al. 1996).

We report a first-generation cytogenetically anchored genetic map based on microsatellites for the rabbit. We have applied a technique using locus-specific primers and three fluorescently labelled universal primers (Schuelke 2000). This technique was successful on $64 \%$ of the markers, allowing us to test a large number of markers and to construct a low-cost genetic map. The reservoir of published microsatellites (Chantry-Darmon et al. 2005b), together with the rabbit whole-genome sequence corresponding to a threefold coverage, will help to increase map density and to provide markers for still-uncovered genomic segments. In addition, because many rabbit microsatellite sequences have hits on the rabbit sequence traces that are released in public databases (data not shown), it is anticipated that our work will help to anchor sequence traces onto the rabbit genome.

\section{Acknowledgements}

We are grateful to Daniel Vaiman and Didier Boichard for their help in designing the rabbit reference families. We acknowledge Xavier Mata for help in reproducing the genotyping data of microsatellites mapping to the X chromosome. We thank the SYSELAF and the Animal Genetics Department at INRA for the financial support of Céline Chantry-Darmon.

\section{References}

Aigner B., Besenfelder U., Seregi J., Frenyo L.V., Sahin-Toth T. \& Brem G. (1996) Expression of the murine wild-type tyrosinase gene in transgenic rabbits. Transgenic Research 5, 405-11.

Aigner B., Besenfelder U., Müller M. \& Brem G. (2000) Tyrosinase gene variants in different rabbit strains. Mammalian Genome 11, 700-2.

Beermann F., Ruppert S., Hummler E., Bosch F.X., Müller G., Rüther U. \& Schütz G. (1990) Rescue of the albino phenotype by introduction of a functional tyrosinase gene into mice. The EMBO Journal 9, 2819-26.

Bishop M.D., Kappes S.M., Keele J.W. et al. (1994) A genetic linkage map for cattle. Genetics 136, 619-39.

Brem G., Besenfelder U., Aigner B., Muller M., Liebl I., Schutz G. \& Montoliu L. (1996) YAC transgenesis in farm animals: Rescue of albinism in rabbits. Molecular Reproduction and Development 44 , $56-62$.

Chantry-Darmon C., Rogel-Gaillard C., Bertaud M., Urien C., Perrocheau M., Chardon P. \& Hayes H. (2003) 133 new gene localizations on the rabbit cytogenetic map. Cytogenetic and Genome Research 103, 192-201.

Chantry-Darmon C., Rogel-Gaillard C., Bertaud M., Urien C., Perrocheau M., Hayes H., Chardon P. \& Hayes H. (2005a) Expanded comparative mapping between man and rabbit and detection of a new conserved segment between HSA22 and OCU4. Cytogenetic and Genome Research 111, 134-9.

Chantry-Darmon C., Urien C., Hayes H., Bertaud M., Chadi-Taourit S., Chardon P., Vaiman D. \& Rogel-Gaillard C. (2005b) Construction of a cytogenetically anchored-microsatellite map in rabbit. Mammalian Genome 16, 442-59.

Fox R.R. (1994) Taxonomy and genetics. In: The Biology of the Laboratory Rabbits, 2nd edn (Ed. by P.J. Manning, D.H. Ringler \& C.E. Newcomer), pp. 1-25. Academic Press, San Diego, CA.

Green P., Falls K. \& Crooks S. (1990) Documentation for CRI-MAP. Washington University School of Medicine, St Louis, MO.

Hayes H., Rogel-Gaillard C., Zijlstra C., De Haan N.A., Urien C., Bourgeaux N., Bertaud M. \& Bosma A.A. (2002) Establishment of an R-banded rabbit karyotype nomenclature by FISH localization of 23 chromosome-specific genes on both G- and R-banded chromosomes. Cytogenetic Genome Research 98, 199-205. 
Hebert J.M., Rosenquist T., Gotz J. \& Martin G.R. (1994) FGF5 as a regulator of the hair growth cycle: evidence from targeted and spontaneous mutations. Cell 78, 1017-25.

Hudson T.J., Engelstein M., Lee M.K., Ho E.C., Rubenfield M.G., Adams C.P., Housman D.E. \& Dracopoli N.C. (1992) Isolation and chromosomal assignment of 100 highly informative human simple sequence repeat polymorphisms. Genomics 13, 622-9.

Jeanpierre M. (1987) A rapid method for the purification of DNA from blood. Nucleic Acids Research 15, 9611.

Korstanje R., O'Brien P.C., Yang F., Rens W., Bosma A.A., van Lith H.A., van Zutphen L.F. \& Ferguson-Smith M.A. (1999) Complete homology maps of the rabbit (Oryctolagus cuniculus) and human by reciprocal chromosome painting. Cytogenetics and Cell Genetics 86, 317-22.

Korstanje R., Gillissen G.F., den Bieman M.G., Versteeg S.A., van Oost B., Fox R.R., van Lith H.A. \& van Zutphen L.F. (2001) Mapping of rabbit chromosome 1 markers generated from a microsatellite-enriched chromosome-specific library. Animal Genetics 32, 308-12.

Korstanje R., Gillissen G.F., Versteeg S.A., van Oost B.A., Bosma A.A., Rogel-Gaillard C., van Zutphen L.F. \& van Lith H.A. (2003) Mapping of rabbit microsatellite markers using chromosomespecific libraries. Journal of Heredity 94, 161-9.

Lebas F., Coudert P., Rouvier R. \& de Rochambeau H. (1997) The Rabbit: Husbandry, Health and Production. FAO Animal Production and Health Series, no. 21, Rome.

Magdelaine P. (2003) Economie et avenir des filières avicoles et cunicoles. INRA Production Animal 16, 349-56.

Mulsant P., de Rochambeau H. \& Thébault R.G. (2004) A note on the linkage between the angora and Fgf5 genes in rabbits. World Rabbit Science 12, 1-6.

Queney G., Ferrand N., Weiss S., Mougel F. \& Monnerot M. (2001) Stationary distributions of microsatellite loci between divergent population groups of the European rabbit (Oryctolagus cuniculus). Molecular Biology and Evolution 18, 2169-78.

de Rochambeau H. (1998) La femelle parentale issue des souches expérimentales de l'INRA: Evolutions génétiques et perspectives. In: 7èmes Journées de la Recherche Cunicole, Lyon (France), pp. 134.
Rogel-Gaillard C., Piumi F., Billault A., Bourgeaux N., Save J.C., Urien C., Salmon J. \& Chardon P. (2001) Construction of a rabbit bacterial artificial chromosome (BAC) library: application to the mapping of the major histocompatibility complex to position 12q.1.1. Mammalian Genome 12, 253-5.

Rohrer G.A., Alexander L.J., Keele J.W., Smith T.P. \& Beattie C.W. (1994) A microsatellite linkage map of the porcine genome. Genetics 136, 231-45.

Sandberg K. \& Andersson L. (1987) Linkage of albino and hemoglobin beta-chain loci in the rabbit. Journal of Heredity 78, 124-5.

Schuelke M. (2000) An economic method for the fluorescent labeling of PCR fragments. Nature Biotechnology 18, 233-4.

Van Haeringen W.A., Den Bieman M., Gillissen G.F., Lankhorst A.E., Kuiper M.T., Van Zutphen L.F. \& Van Lith H.A. (2001) Mapping of a QTL for serum HDL cholesterol in the rabbit using AFLP technology. Journal of Heredity 92, 322-6.

Van Haeringen W.A., Den Bieman M.G., Lankhorst A.E., van Lith H.A. \& van Zutphen L.F. (2002) Application of AFLP markers for QTL mapping in the rabbit. Genome 45, 914-21.

Vrillon J.L., Thebault R.G., Allain D. \& de Rochambeau H. (1998) La fourrure d'Orylag: une nécessaire relation de séduction associée à la démarche d'amélioration génétique. In: 7èmes Journée de la Recherche Cunicole Française (Lyon), pp. 91-8.

Xu J. \& Hardison R.C. (1989) Localization of the beta-like globin gene cluster and the genes for parathyroid hormone and c-Harvey-ras 1 to region q14-q21 of rabbit chromosome 1 by in situ hybridization. Cytogenetics and Cell Genetics 52, 157-61.

\section{Supplementary Material}

The following supplementary material is available online at http://www.blackwell-synergy.com:

Table S1 Polymorphism of rabbit microsatellites.

Table S2 Summary of the data associated with microsatellites integrated in the genetic map.

Appendix S1 Genotyping PCR conditions. 